\title{
Kinetics and mechanisms of congo-red dye removal from aqueous solution using activated Moringa oleifera seed coat as adsorbent
}

\author{
Jamiu M. Jabar ${ }^{1}$ (D) Y Yisau A. Odusote ${ }^{2} \cdot$ Kazeem A. Alabi $^{3} \cdot$ Ibrahim B. Ahmed $^{1}$
}

Received: 17 June 2019 / Accepted: 30 April 2020 / Published online: 15 May 2020

(c) The Author(s) 2020

\begin{abstract}
Moringa oleifera (MO) seed coat, a postharvest waste of MO seed, was mercerized and used as eco-friendly adsorbent for removal of Congo red (CR) dye from aqueous solution at different time and temperature. Mercerized M. oleifera seed coat (MSC) was characterized through scanning electron microscopy (SEM) and Fourier transform infrared spectroscopy (FTIR) before and after adsorption process. Data obtained from effect of contact time on CR dye-uptake were applied on Elovich, pseudo-first- and second-order kinetic models, as well as on intraparticle diffusion and Boyd models. SEM and FTIR showed adsorption of CR dye on MSC through filled holes (SEM), appearance of new and shifting existing of functional groups (FTIR) on the surface of MSC after adsorption process. Adsorption kinetics was seen to be best fitted with pseudo-secondorder model with the highest value of correlation coefficient at all temperatures. Film diffusion mechanism controlled the adsorption process, where external mass transfer was higher than internal mass transfer. Adsorption kinetics parameters confirmed removal of CR dye from aqueous solution through chemical and physical adsorption on MSC.
\end{abstract}

Keywords Adsorption kinetics $\cdot$ Film diffusion $\cdot$ Dye uptake $\cdot$ Model $\cdot$ Moringa oleifera

\section{Introduction}

Congo red (CR) dye is a disazo synthetic dye, characterized by large molecular structure with two azo group $(\mathrm{N}=\mathrm{N})$ that are bond to aromatic rings having linear and planar molecular structure (Dhaif-Allah et al. 2020; Christie 2015; Rong et al. 2015). Presently, synthetic dye covers about $60-70 \%$ of total coloring matter used in chemical and allied industries (Cheng et al. 2015). CR dye is used in dye house for coloring textile, pulp/paper, making paint, etc. (due to its intense color, high affinity and fastness properties), (Chen and Zhao 2009) as pH indicator in chemical laboratory and for microbial staining (Chukki et al. 2018). Its effluent from these industries, if not properly treated before being discharged into the water bodies, can cause

Jamiu M. Jabar

jmjabar@futa.edu.ng

1 Chemistry Department, The Federal University of Technology, P.M.B. 704, Akure, Nigeria

2 Physcis Department, The Federal University of Technology, P.M.B. 704, Akure, Nigeria

3 Department of Chemical Sciences, Fountain University, P.M.B 4491, Osogbo, Nigeria severe injury to aquatic habitants and human beings that use water from those receiving water bodies for domestic purpose (Somasekharareddy et al. 2012). The injury to aquatic habitants can be through reduction in phytoplankton photosynthesis and water dissolved oxygen (Fisli et al. 2014). Formation of benzidine by CR dye in receiving water body can cause human cancer of the breast, skin or throat (Chatterjee et al. 2007). Several researchers have tried to remove coloring matter from wastewater by biological (assimilation, enhanced biological dye removal, wastewater stabilization) methods (Aljeboree et al. 2014; Chatterjee and Woo 2010; Hu et al. 2010), photocatalytic degradation (Amaranatha et al. 2015) and chemical (precipitation, coagulation, flocculation, crystallization and ion exchange) methods (Pathania et al. 2017; Babu et al. 2015). Others are physical (microfilteration, reverse osmosis, electrodialysis, magnetic separation and adsorption) methods (Tang et al. 2014). Among all these methods of removal of dye from aqueous solution, adsorption process is seen to be the best method (El Haddad et al. 2013). The frequently used adsorbent in wastewater treatment by adsorption technique is commercial activated carbon (CAC). This was due to its high uptake capacity, high surface area, environment friendly, easy to operate, simple, time saving and non-toxic

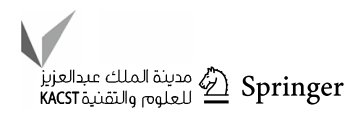


nature (Salleh et al. 2011). Recently, researchers are now finding alternative to the use of CAC in wastewater treatment due to high cost of operation involved (Jabar and Odusote 2020). Some of the synthetic adsorbents tried by some researchers as alternative to CAC are $\mathrm{Zn}_{0.3} \mathrm{Fe}_{0.45} \mathrm{O}_{3}$ (Jethava and Fegade 2018), modified zeolites (Liu et al. 2014), synthesized MgO (Li 2019) and nano-fiber (Bhaumik et al. 2013), but high cost, non-biodegradability and regeneration of many of these adsorbents made researchers to be looking into green materials as possible alternative. Plant derived adsorbents seen to be in front line of these alternative to CAC in adsorption technology, probably due to availability at visually no cost and high regeneration ability, besides other desired attributes of CAC (Jabar and Odusote 2020). Some plant materials used as adsorbents for removal of CR dye and other classes of dye from aqueous solution are oil palm empty fruit bunch fiber (Jabar and Odusote 2020), fenugreek seed spent (Dhaif-Allah et al. 2020), groundnut shell (Bayuo et al. 2019), Moringa oleifera leaf (Bello et al. 2017), aloe vera leaves wastes (OmidiKhaniabadi et al. 2016), aloe vera green wastes (OmidiKhaniabadi et al.2015), jujuba seeds (Reddy et al. 2012), bagasse (Zhang et al. 2011), rice husk (Han et al. 2008) and Azadirachta indica leaf (Bhattachrrya and Sharma 2004) to mention just a few. Mercerization of MO seed coat as adsorbent in removal of dye from industrial or simulated effluent has not been reported to the best of our knowledge.

Moringa oleifera (MO) plant is a native of India, presently grown in many parts of the world. In Nigeria, it is grown for food and medicinal purposes (Siddhuraju and Becker 2003). When matured, the plant is $10-13 \mathrm{~m}$ in height and $30-35 \mathrm{~cm}$ width with brown fruit containing 10-24 seeds. Postharvest of MO seeds generates seed coats as environment waste (Bello et al. 2017). Conversion of this waste to adsorbent for removal of dye from aqueous solution is a good technique for conversion of waste to wealth (Bayuo et al. 2019). The aim of this research is to develop a novel adsorbent from MO seed coat through mercerization process. This adsorbent was used to remove CR dye from aqueous solution, kinetics, and mechanisms of adsorption processes were investigated.

\section{Experimental methods}

\section{Materials}

MO seed coat was obtained from Itaoniyan road, along old Akure-Ondo road Akure. It was authenticated at Department of Crop, Soil and Pest Management, Federal University of Technology, Akure, Nigeria. CR dye stuff and sodium hydroxide used are Anal reagents obtained from SigmaAldrich Chemical, Germany.

\section{Preparation of adsorbent}

MO seed coat was washed several times with water to remove adhered impurity, oven-dried at $105^{\circ} \mathrm{C}$ to a constant weight and ground with an electrical blender. Purified MO seed coat was chemically activated as described by Ozsin et al. (2019) with slight modification. It was soaked in $5 \% \mathrm{NaOH}$ solution for $2 \mathrm{~h}$, washed several time with distilled water to neutral $\mathrm{pH}$. Sodium hydroxide-modified MO seed coat was oven-dried at $105^{\circ} \mathrm{C}$ to a constant weight to obtain chemically modified $M$. oleifera seed coat (MSC). MSC was then crushed and sieved to particle size between 150-170 $\mu \mathrm{m}$. This was used for adsorption without any further modification.

\section{Characterization of MSC adsorbent}

Scanning electron micrographs (SEM) of the MSC (before and after adsorption process) were taken in an XL 20 Philips SEM. The surface of the fibers was studied with the microscope operated at $10.0 \mathrm{kV}$. The samples were coated with a 10-nm-thick layer of gold.

Fourier transform infrared spectroscopic (FTIR) method of analysis was used in determination of functional groups in MSC before and after adsorption process. The infrared spectra of the MSC (before and after adsorption process) were obtained by using MSC mixed with potassium bromide at ratio 1:100 in a mortar pestle. The mixture was then taken in a dice of specific dimension to form pellet by pressing with a hand press machine, placed on the sample holder of the IR spectrometer (PerkinElmer) operated at spectral range $4000-500 \mathrm{~cm}^{-1}$.

Other properties of MSC determined are moisture content, ash content, surface area (Sear method) and $\mathrm{pH}$ (ASTMD 3838-80).

\section{Preparation and standardization of CR dye liquor}

CR dye (10 mg) was accurately weighed into $250 \mathrm{~mL}$ conical flask, and distilled water $(10 \mathrm{~mL})$ was added to make a paste. The paste was stirred; little more quantity of distilled water was added and stirred for total dissolution of the dye. The dissolved dye solution was transferred into the $1 \mathrm{~L}$ standard flask and made up to marked point with distilled water.

The aqueous dye solution was standardized on UV-visible spectrophotometer (Pharmacia LKB Biochrome 4060). Its wavelength at maximum absorption $\left(\lambda_{\max }\right)$ was found to be $500 \mathrm{~nm}$, and this was used to measure the absorbance of serially diluted solutions made from stock solution $(2,4$, 
$6,8,10 \mathrm{mg} / \mathrm{L})$. Subsequently, absorbance of the dye effluent after each of adsorption processes was measured to provide means of evaluating the percentage dye removed, dye-uptake at particular time and at equilibrium by the adsorbent used.

\section{Impact of contact time on adsorption process}

Batch adsorption study was carried out on effect of contact time on dye removal using $20 \mathrm{~mL}$ CR dye solution in $100 \mathrm{~mL}$ conical flask on water bath shaker at shaking speed of $100 \mathrm{rpm}$. The adsorption processes were carried between temperature of 301 and $321 \mathrm{~K}$ at $10 \mathrm{~K}$ interval. Initial dye concentration was $10 \mathrm{mg} / \mathrm{L}, 0.1 \mathrm{~g}$ of adsorbent dosage, and adsorption time was varied from 15-150 min. After each of the adsorption experiments, MSC was separated from dye effluent by centrifugation using centrifuge at room temperature, rotation speed of $5000 \mathrm{rpm}$ for $10 \mathrm{~min}$.

Absorbance of aliquot of dye effluent was read on UV-visible spectrophotometer and concentration interpolated from working graph. The percentage $\mathrm{CR}$ dye adsorbed on the surface of MSC was determined by difference of the two concentrations (AlOthman et al. 2013) as shown in Eq. 1.

$\% R=\frac{\left(C_{\mathrm{o}}-C_{\mathrm{t}}\right)}{C_{\mathrm{o}}} \times 100 \%$

The amount of CR adsorbed per unit weight of MSC (dye-uptake $(\mathrm{mg} / \mathrm{g})$ at a particular time and at equilibrium (Hameed et al. 2013) was calculated as shown in Eqns. 2 and 3 .

$q_{\mathrm{t}}=\frac{\left(C_{\mathrm{o}}-C_{\mathrm{t}}\right)}{W} \times \mathrm{V}$

$q_{\mathrm{e}}=\frac{\left(C_{\mathrm{o}}-C_{\mathrm{e}}\right)}{W} \times \mathrm{V}$

where $\% R$ is percentage CR dye removed, $C_{\mathrm{o}}$ is the initial dye concentration $(\mathrm{mg} / \mathrm{L}), C_{\mathrm{t}}$ and $C_{\mathrm{e}}$ are the concentration of dye effluent after adsorption $(\mathrm{mg} / \mathrm{L})$ at particular time and equilibrium, respectively; $V$ is the volume of dye solution (L), $W$ is the weight of adsorbent $(\mathrm{g}), q_{\mathrm{t}}$ and $q_{\mathrm{e}}$ are the dye-uptake $(\mathrm{mg} / \mathrm{g})$ at a particular time and at equilibrium, respectively.

\section{Adsorption kinetic modeling}

A precise design of wastewater treatment plant using adsorption technique requires accurate information on kinetic rate of removal of pollutants from wastewater. Supplying this information requires treatment of data obtained from effect of contact time on adsorption process. In this work, the data obtained from effect of contact time on quantity of CR dye adsorbed at the surface of MSC were used in Lagergren pseudo-first-order (Eq. 4), pseudo-second-order (Eq. 5) and Elovich kinetic models (Eq. 6) as described by Aljeboree et al. (2014).

$\log \left(q_{\mathrm{e}}-q_{\mathrm{t}}\right)=\log q_{\mathrm{e}}-\left(\frac{k_{1}}{2.303}\right) t$

$\frac{t}{q_{\mathrm{t}}}=\frac{1}{h_{2}}+\left(\frac{1}{q_{\mathrm{e}}}\right) t$

where $h_{2}=k_{2} q_{e}{ }^{2}$

$q_{\mathrm{t}}=\left(\frac{1}{\beta}\right) \ln (\alpha \cdot \beta)+\left(\frac{1}{\beta}\right) \ln (t)$

where $q_{\mathrm{e}}$ and $q_{\mathrm{t}}(\mathrm{mg} / \mathrm{g})$ are dye-uptake at equilibrium and at time $t$, respectively, $k_{1}$ is rate constant of pseudo-first-order adsorption ( $\mathrm{mg} / \mathrm{g} \min ), h_{2}$ is initial adsorption rate $(\mathrm{mg} / \mathrm{g})$, $k_{2}$ is rate constant of pseudo-second-order adsorption $(\mathrm{g} /$ $\mathrm{mg}$ ), $\beta$ is extent of surface coverage ( $\mathrm{min} \mathrm{g} / \mathrm{mg}$ ), $\alpha$ is rate of adsorption ( $\mathrm{mg} / \mathrm{g} \mathrm{min}$ ) and $t$ is time ( $\mathrm{min})$.

Suitability of any of these models to best fit with adsorption process is the closeness of experimented dyeuptake $\left(q_{\mathrm{e}(\exp )}\right)$ at equilibrium to calculated dye-uptake $\left(q_{\mathrm{e}(\mathrm{cal})}\right)$ in pseudo-first- and second-order kinetic models. Other factors that determine best suitable kinetic are values of correlation coefficient $R^{2}$ and sum of square error SSE (Eq. 7). The higher the value of $R^{2}$ and the lower the value of SSE, the more fit the model. $\mathrm{N}$ is number of data points (Pura and Atun 2009).

$\mathrm{SSE}=\frac{\sqrt{\sum\left(q_{\mathrm{e}(\mathrm{cal})}-\mathrm{q}_{\mathrm{e}(\mathrm{exp})}\right)^{2}}}{N}$

Arrhenius expression (1889), that linked pseudo-second-order rate constant $k_{2}$ to temperature (Eq. 8), can be used to predict type of adsorption process.

$k_{2}=k_{o} e^{-E_{a} / R T}$

where $k_{2}$ is rate constant of pseudo-second-order, $k_{\mathrm{o}}$ is the frequency factor $\left(\mathrm{gmg}^{-1}\right), R$ is the gas constant $(8.314 \mathrm{~J} / \mathrm{mol} \mathrm{K})$ and $E_{\mathrm{a}}$ is activation energy for adsorption process $(\mathrm{kJ} / \mathrm{mol})$ and $T$ is absolute temperature $(\mathrm{K})$. If the value of $E_{\mathrm{a}} \geq 40 \mathrm{~kJ} / \mathrm{mol}$, the type of adsorption process is chemisorption, but if otherwise it is physisorption (Bannerjee and Chattopadhyyaya 2017). 


\section{Adsorption mechanism}

Mechanism of adsorption process was deduced from intraparticle diffusion (Eq. 9) and Boyd kinetic models (Eqs. 10-13) using data obtained from effect of contact time on adsorption process as described by (Kumar and Kumaran 2005).

$q_{t}=k_{\mathrm{id}} t^{0.5}+C$

Intraparticle diffusion was used to determine type of adsorption mechanism in the process. If the graph of $q_{t} \mathrm{Vs}$ $t^{0.5}$ is linear and passes through the origin, it means intraparticle diffusion is rate determining step. If otherwise, it means other mechanism is involved together with intraparticle diffusion (Sartape et al. 2014). Boyd expression in (Eq. 10) generates Eq. 13, which can be used to determine type of mechanism involved (Boyd et al. 1947).

$F=1-\frac{6}{\pi^{2}} \sum_{1}^{\infty}\left(\frac{1}{n^{2}}\right) \exp \left(-\mathrm{n}^{2} B_{\mathrm{t}}\right)$

$B_{\mathrm{t}}=-0.499-\ln (1-F)$

$F=\frac{q_{\mathrm{t}}}{q_{e}}$

$B_{t}=B(t)+C$

where $q_{t}$ and $q_{\mathrm{e}}$ are dye-uptake $(\mathrm{mg} / \mathrm{g})$ at time $t$ and equilibrium, respectively, $k_{\text {id }}$ is the initial rate of intraparticle diffusion ( $\left.\mathrm{mg} / \mathrm{g} \mathrm{min}^{1 / 2}\right), C$ is intercept that gives information about thickness of the boundary layer, $F$ is the fraction of dye-uptake and $B_{\mathrm{t}}$ is the mathematical function of $F$ and $B$ is time constant $\left(\mathrm{min}^{-1}\right)$ gotten from slope of $B_{\mathrm{t}} \mathrm{Vs} t$.

If plot of $B_{\mathrm{t}} \mathrm{Vs} t$ is linear and passes through the origin, it indicates that adsorption process is controlled by pore (particle) diffusion mechanism, where internal transport of CR dye is greater than external transport. If it does not pass through the origin, it indicates film diffusion controls adsorption process, where external transport is greater than internal transport (Boyd et al. 1947).

\section{Results and discussion}

\section{Characterization of MSC}

The SEM image of MSC before adsorption (Fig. 1) shows the presence of holes on its surface. These holes are the available pores at the surface of adsorbent, where CR dye molecules are to be captured from aqueous solution

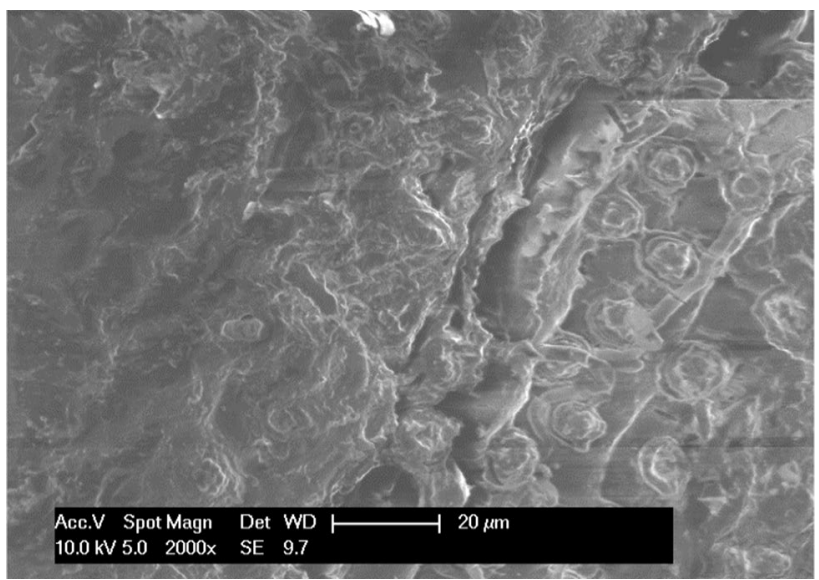

Fig. 1 SEM micrograph of MSC before adsorption of CR dye

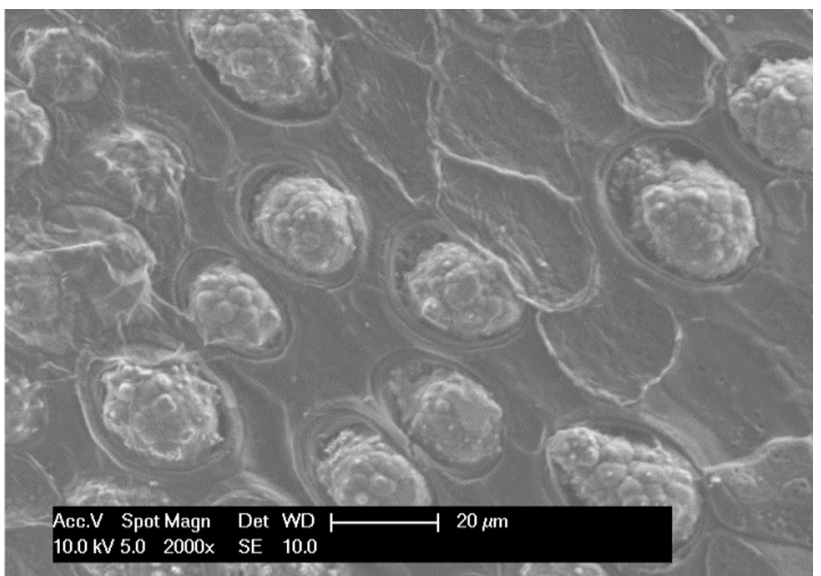

Fig. 2 SEM micrograph of MSC after adsorption of CR dye

(Li 2019). After adsorption process, SEM image of MSC (Fig. 2) displayed the captured dye molecules at the surface of the adsorbent. The captured dye molecules got to fill the available pores in MSC by diffusion of CR dye molecules from aqueous solution to MSC surface through its boundary layer. This was followed by migration of dye molecules from MSC surface to inner pores of the adsorbent and finally adsorbed at the available sites on its surface. The adsorption of CR dye at the surface of MSC might be physical adsorption (physiosoption), through mechanical adhesion of adsorbate on adsorbent. This observation agreed with Boulaiche et al. (2019).

The characteristic functional groups in MSC before and after adsorption of CR from aqueous solution were identified from FTIR spectra in Figs. 3 and 4, respectively. Broad peak at $3271.38 \mathrm{~cm}^{-1}$ indicates the presence of $-\mathrm{OH}$ stretching vibration of phenols and alcohols in lignin and cellulose of MSC before adsorption process (Fig. 3). Other peaks in spectrum of MSC before CR dye adsorption are 


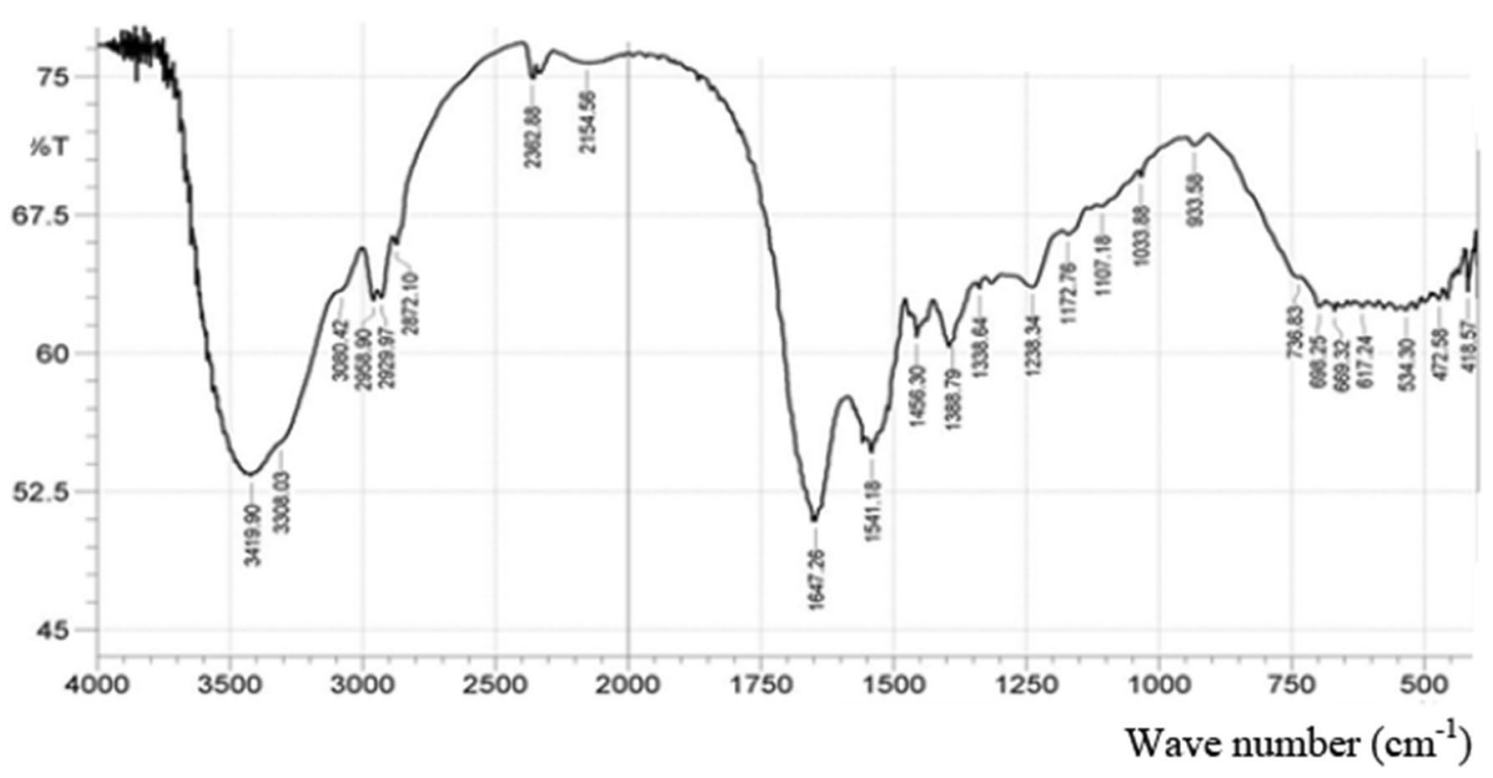

Fig. 3 FTIR spectrum of MSC before adsorption of CR dye

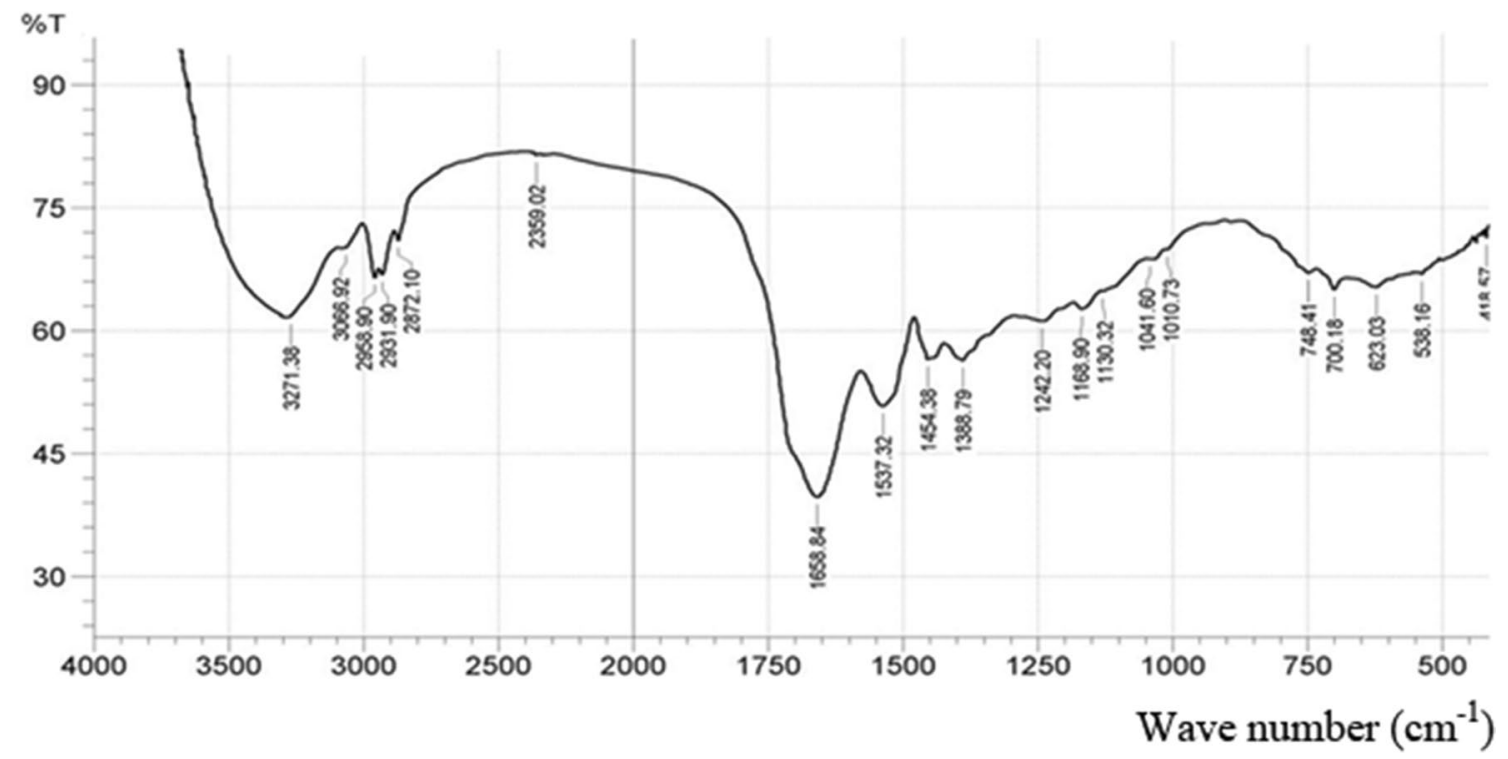

Fig. 4 FTIR spectrum of MSC after adsorption of CR dye

2931.90, 1658.84, 1388.79 and $1041.60 \mathrm{~cm}^{-1}$. These are due to $-\mathrm{CH}_{2},-\mathrm{C}=\mathrm{C}, \mathrm{C}-\mathrm{C}$ and $\mathrm{C}-\mathrm{O}$ stretching, respectively (Bello et al. 2017). MSC spectrum after CR dye adsorption (Fig. 4) has additional peaks at 3419.90, 1172.76 and $698.25-669.32 \mathrm{~cm}^{-1}$. These peaks are due to $-\mathrm{NH}_{2}, \mathrm{C}-\mathrm{N}$ and $\mathrm{SO}_{3}{ }^{-}$functional groups in $\mathrm{CR}$ dye. These affirmed the removal of CR dye molecules from aqueous solution after adsorption through electrostatic force (chemisorption). The observation is in line with findings made by $\mathrm{Li}$ (2019), in combustion synthesis of porous $\mathrm{MgO}$ and its adsorption properties. However, the peaks at 3271.38, 2931.90,
$1658.84,1388.79$ and $1041.60 \mathrm{~cm}^{-1}$ are shifted to 3308.05 , $2958.90,1647.26,1388.79$ and $1033.88 \mathrm{~cm}^{-1}$, respectively. This shift in absorption bands of MSC after adsorption process suggested the interactions of functional groups in dye molecules with those of MSC adsorbent according to Pathania et al. (2017).

The values of moisture content (MC), ash content (AC), bulk density (BD), surface area (SA) and $\mathrm{pH}$ as physicochemical properties of MSC are shown in Table 1. The literature shows that the acceptable adsorbents for treatment of wastewater have $\mathrm{pH}$ value range from 6.0-8.0 (Bello et al. 
Table 1 Physicochemical properties of MSC

\begin{tabular}{ll}
\hline Properties & Results \\
\hline Moisture content $(\%)$ & 2.94 \\
Ash content $(\%)$ & 5.24 \\
Bulk density $\left(\mathrm{gcm}^{-3}\right)$ & 0.110 .11 \\
Surface area $\left(\mathrm{cm}^{2} \mathrm{~g}\right)$ & 55.00 \\
$\mathrm{pH}$ & 7.40 \\
\hline
\end{tabular}

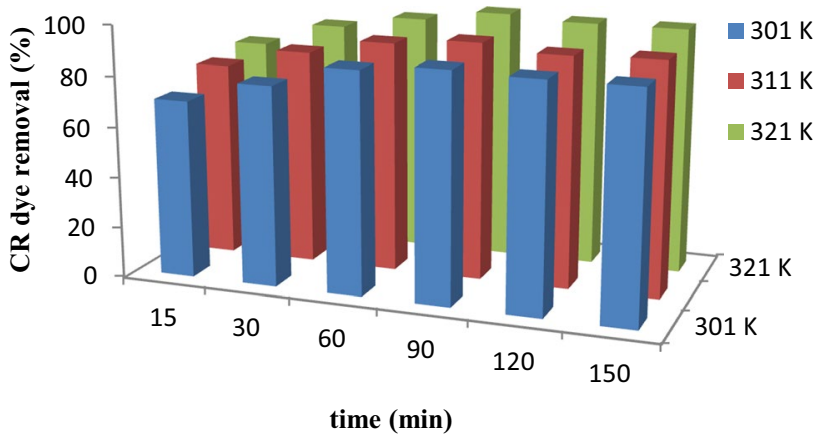

Fig. 5 Effect of contact time on percentage CR dye removed from aqueous dye solution at different temperatures

2017). The $\mathrm{pH}$ value (7.4) of MSC affirmed acceptability of MSC as an alternative adsorbent from biomass for removal of CR dye and related impurities from aqueous solution according Bello et al. (2017). The MC value (low) shows that MSC has a good potential of removing large amount of CR dye from its aqueous solution. Low AC indicated that large amount of volatile matter had been removed during the mercerization process of the adsorbent (Bello and Ahmad 2012). However, the lower the volatile matter, the higher the number of voids/pores in the adsorbent and the higher will be the magnitude of SA (Bello and Semire 2012). The high SA showed that MSC has high potential of dye removal efficiency. The value of BD indicates that large quantity of wastewater that can be treated by the adsorbent, the lower the BD the better the adsorptive potential of the adsorbent (Bello et al. 2011). Hence, low BD value indicated that MSC is a potential adsorbent for removing $\mathrm{CR}$ dye from aqueous solution.

\section{Effect of contact time on dye removal and dye-uptake}

The quantity of dye removed from aqueous solution by MSC increased as the time of adsorption increases up to $90 \mathrm{~min}$ of adsorption process (Fig. 5). After 90 min of adsorption, quantity of CR dye removed declined, this showed that optimum time of adsorption process is $90 \mathrm{~min}$. This observation is in line with Chukki et al. (2018). The rapid increase in

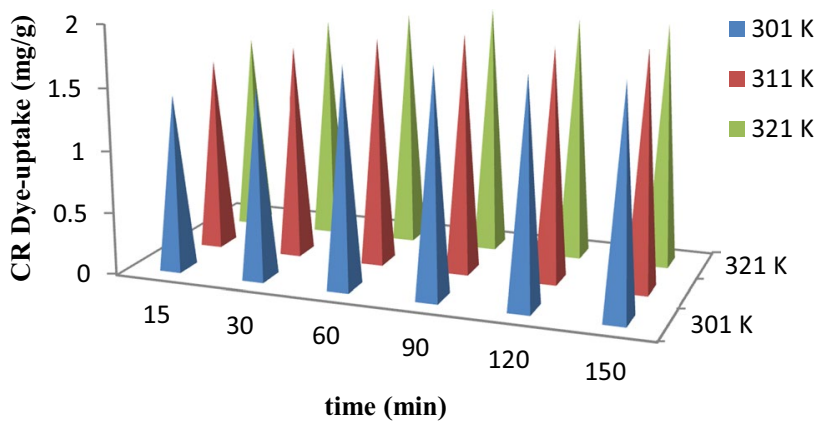

Fig. 6 Effect of contact time on dye-uptake of CR dye adsorbed from aqueous solution at different temperatures

Table 2 Comparison of optimum contact time of various adsorbents towards CR dye adsorption

\begin{tabular}{lll}
\hline Adsorbent & $\begin{array}{l}\text { Contact } \\
\text { time } \\
(\mathrm{min})\end{array}$ & References \\
\hline $\mathrm{Zn}_{0 \cdot 3} \mathrm{Fe}_{0 \cdot 45} \mathrm{O}_{3}$ nanoparticle & 40 & Jethave and Fagade, (2018) \\
Synthesized $\mathrm{MgO}$ & 60 & $\mathrm{Li} \mathrm{(2019)}$ \\
$\begin{array}{l}\text { Chrysanthemum indicum } \\
\begin{array}{l}\text { Mercerized Moringa seed } \\
\text { pod }\end{array}\end{array}$ & 90 & Chukki et al. (2018) \\
\hline
\end{tabular}

CR dye removal at initial stage up to 90 min might be due to availability of active sites at the surface of MSC. After $90 \mathrm{~min}$ of adsorption, vacant active sites got filled up by CR dye molecules; this might cause repulsive force between dye molecule on MSC and those in solution (Etim et al. 2016). The repulsive force might result into reduction in quantity of dye adsorbed after $90 \mathrm{~min}$. This observation is in line with the findings of Deng and Shi (2015) in synthesis and characterization of novel $\mathrm{Mg}-\mathrm{Al}$ hydrotacite-loaded kaolin clay and its adsorption properties for phosphate in aqueous solution. The same trend of adsorption pattern seen in effect of contact time on dye removal was observed in effect of contact time on dye-uptake (Fig. 6). Optimum contact time for removal of CR dye from aqueous solution using different adsorbent is shown in Table 2. It can be seen from Figs. 5 and 6 that adsorption at $321 \mathrm{~K}$ has the highest percentage dye removal/uptake, while that at $301 \mathrm{~K}$ has the lowest percentage dye removal/uptake among all the processing temperatures. This might be as a result of increase in kinetic energy of CR dye molecules and efficiency of the adsorbent as temperature increased (Banerjee et al. 2017).

\section{Adsorption kinetic models}

Three kinetic models were used to investigate the effect of contact time on CR dye removal from its aqueous solution. These kinetic studies show relationship between the 


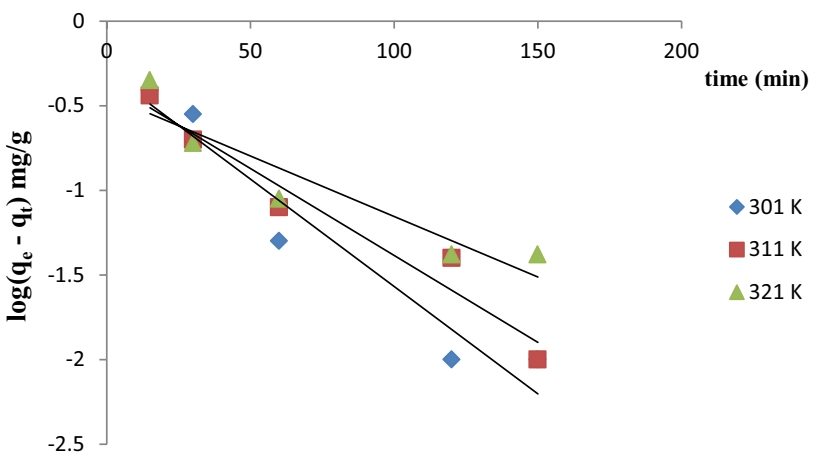

Fig. 7 Pseudo-first-order kinetic plots for adsorption of CR dye on MSC at different temperatures

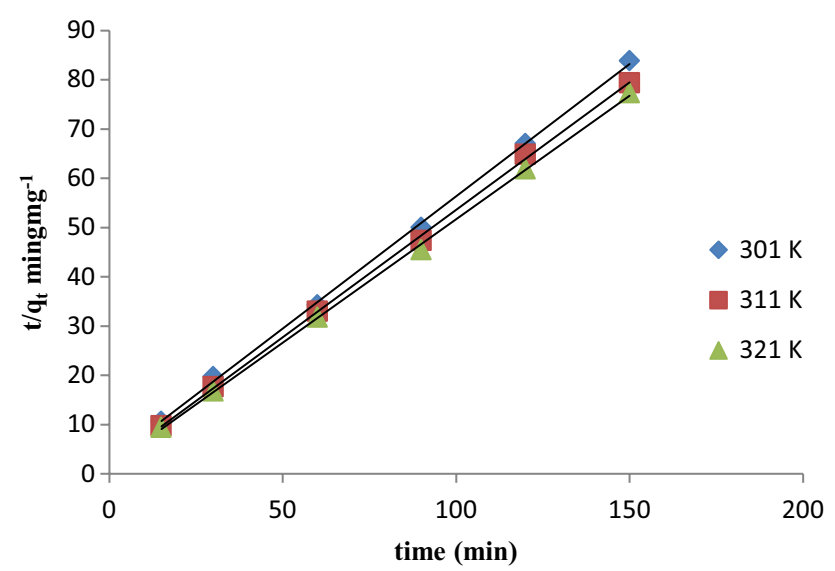

Fig. 8 Pseudo-second-order kinetic plots for adsorption of CR dye on MSC at different temperatures

quantity of adsorbate removed and time of removal from aqueous solution (Yan et al. 2015).

Pseudo-first-order kinetic obeys law of mass action (Hameed et al. 2013), which state that rate of adsorption reaction is proportional to the dye-uptake on the adsorbent from dye solution (Eq. 14).

$\log \frac{q_{t}}{d_{\mathrm{t}}}=k_{1}\left(q_{\mathrm{e}}-q_{t}\right)$

where: $q_{e}=$ Dye-uptake at equilibrium $(\mathrm{mg} / \mathrm{g}), q_{t}=$ Dye uptake at a particular time $(\mathrm{mg} / \mathrm{g}), \mathrm{K}_{1}=$ pseudo-first-order rate constant $\left(\mathrm{mgg}^{-1} \mathrm{~min}^{-1}\right), \mathrm{t}=$ adsorption time (min).

The linearized form of Eq. 14 is shown in Eq. 4. The slope and intercept of graph of $\log \left(q_{e}-q_{\mathrm{t}}\right) \mathrm{Vs} t$ (Fig. 7) were used to determine rate constant $K_{1}$ and calculated dye-uptake $q_{\mathrm{e} \text {,(cal.) }}$, respectively.

Pseudo-second-order kinetic shows that the rate of adsorption process is proportional to square of dye-uptake by the adsorbent (Eq. 15) (Chan-Li et al. 2007).

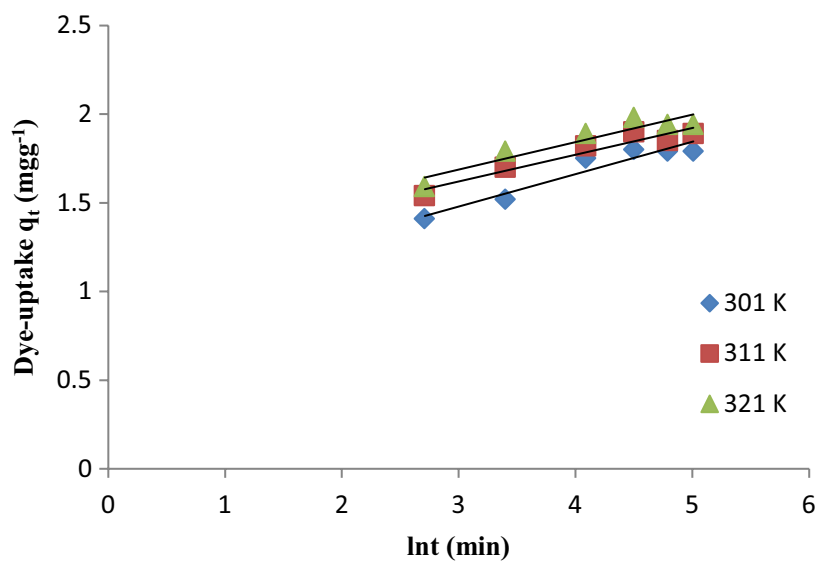

Fig. 9 Elovich kinetic plots for adsorption of CR dye on MSC at different temperatures

Table 3 Kinetic parameters for adsorption of CR dye on MSC at different temperatures

\begin{tabular}{|c|c|c|c|}
\hline \multirow[t]{2}{*}{ Parameter } & \multicolumn{3}{|c|}{ Temperature (K) } \\
\hline & 301 & 311 & 321 \\
\hline$q_{\mathrm{e}(\exp .)}(\mathrm{mg} / \mathrm{g})$ & 1.80 & 1.90 & 1.98 \\
\hline \multicolumn{4}{|c|}{ Pseudo-first-order kinetic } \\
\hline$q_{\mathrm{e}(\mathrm{cal} . .)}(\mathrm{mg} / \mathrm{g})$ & 0.50 & 0.44 & 0.32 \\
\hline$k_{1}\left(\mathrm{mgg}^{-1} \min ^{-1}\right)$ & $2.92 \times 10^{-2}$ & $2.37 \times 10^{-2}$ & $1.62 \times 10^{-2}$ \\
\hline$R^{2}$ & 0.9340 & 0.9539 & 0.873 \\
\hline SSE (mg/g) & 0.22 & 0.24 & 0.28 \\
\hline \multicolumn{4}{|c|}{ Pseudo-second-order kinetic } \\
\hline$q_{\mathrm{e}(\mathrm{cal} . .)}(\mathrm{mg} / \mathrm{g})$ & 1.86 & 1.93 & 2.00 \\
\hline$k_{2}\left(\mathrm{gmg}^{-1}\right)$ & 0.11 & 0.14 & 0.16 \\
\hline$h_{2}\left(\mathrm{mgg}^{-1}\right)$ & 9.18 & 7.12 & 6.34 \\
\hline$R^{2}$ & 0.9984 & 0.9994 & 0.9994 \\
\hline $\mathrm{SSE}(\mathrm{mg} / \mathrm{g})$ & 0.010 & 0.005 & 0.003 \\
\hline \multicolumn{4}{|l|}{ Elovich } \\
\hline$B\left(\mathrm{mgg}^{-1} \min ^{-1}\right)$ & 5.47 & 6.63 & 6.04 \\
\hline$\alpha(\min )$ & 30.06 & 346.52 & 436.99 \\
\hline$R^{2}$ & 0.9149 & 0.9117 & 0.8749 \\
\hline \multicolumn{4}{|c|}{ Arrhenius expression } \\
\hline$k_{\mathrm{o}}\left(\mathrm{gmg}^{-1}\right)$ & 2.492 .49 & & \\
\hline$E_{\mathrm{a}}(\mathrm{kJ} / \mathrm{mol})$ & $2.01 \times 10^{-3}$ & & \\
\hline$R^{2}$ & 0.9909 & & \\
\hline
\end{tabular}

$\frac{\mathrm{d} q_{\mathrm{t}}}{\mathrm{d} t}=k_{2}\left(q_{\mathrm{e}}-q_{\mathrm{t}}\right)^{2}$

The linearized form of Eq. 15 is shown in Eq. 5. The slope and intercept of graph of $t / q_{t}$ Vs $t$ (Fig. 8) were used to obtain calculated dye-uptake $q_{\mathrm{e}(\mathrm{cal})}$ and rate constant $K_{2}$, respectively. 
The linear form of Elovich equation is shown in Eq. 6. The slope and intercept of the graph of $q_{t} \mathrm{Vs} \ln t$ (Fig. 9) were used to calculate extent of surface coverage $\beta(\mathrm{g} / \mathrm{mg})$ and adsorption rate $\alpha$ ( $\mathrm{mg} / \mathrm{g} \mathrm{min})$. The rate constants, calculated dye-uptake, correlation coefficient and other kinetic constant from the three models studied are presented in Table 3. These calculated kinetic constants indicated pseudosecond-order kinetic with highest correlation coefficient $R^{2}$ to fit best. Kinetic does not apply to pseudo-first-order and Elovich model according to Boulaiche et al. (2019). Equally, calculated dye-uptake in pseudo-first-order kinetic is by far less than one obtained from experiment $\left(q_{\mathrm{e}(\mathrm{cal})}<<q_{\mathrm{e}(\exp )}\right)$. Whereas, in pseudo-second-order kinetic, the dye-uptake calculated is closer to that obtained from experiment. This further confirms fitness of kinetic studies with pseudosecond-order. This observation agreed with the findings of Hameed et al. (2007) in adsorption of basic dye onto activated carbon prepared from rattan saw dust. The fitness of the models was further tested on values of sum of square error using Eq. 7. It was seen that pseudo-second-order has lower values of SSE (Table 3) indicating kinetic models best fit with pseudo-second-order kinetic and possibility of $\mathrm{CR}$ dye adsorption on MSC through chemisorption according to Darwish et al. (2019). Arrhenius expression (Eq. 8) that shows relationship between pseudo-second-order rate constant $k_{2}$ and temperature was used to confirm type of adsorption process. The linearized Arrhenius expression (Eq. 16) was used to predict type of adsorption process by plotting $\ln k_{2}$ Vs $T^{-1}$ (Fig. 10). The slope and intercept of the graph were used to calculate activation energy $\left(E_{\mathrm{a}}\right)$ and frequency factor $\left(k_{\mathrm{o}}\right)$ of adsorption process, respectively.

$\ln k_{2}=\ln k_{\mathrm{o}}-\frac{E_{\mathrm{a}}}{R}\left(\frac{1}{T}\right)$

The activation energy $E_{\mathrm{a}}$ was found to be $2.01 \mathrm{~kJ} / \mathrm{mol}$, and frequency factor $k_{\mathrm{o}}$ was 0.9153 . Value of activation energy $\left(E_{\mathrm{a}}\right)$ less than $40 \mathrm{~kJ} / \mathrm{mol}$ shows that adsorption of $\mathrm{CR}$ dye

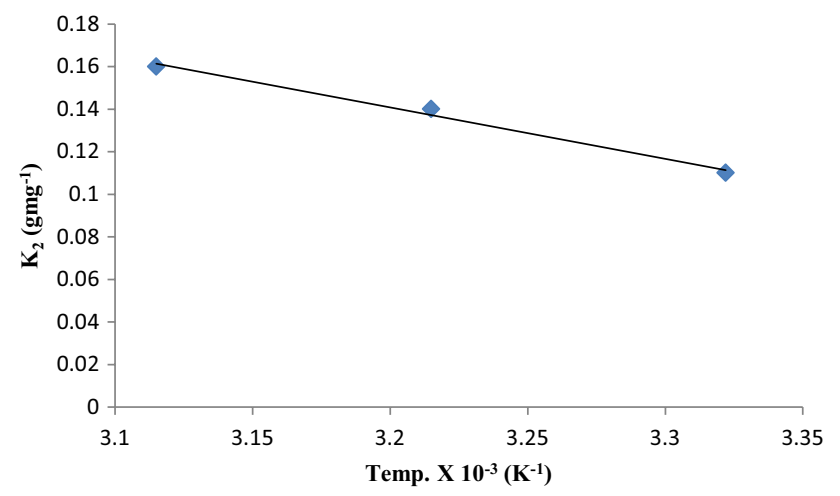

Fig. 10 Arrhenius plot for adsorption of CR dye on MSC onto MSC might be through physisorption according to Bannerjee and Chattopadhyyaya (2017). Therefore, one can say that CR dye was removed from aqueous solution using MSC as adsorbent through physiso-chemisorption process.

\section{Mechanism of adsorption kinetic}

Two models used to investigate mechanism of adsorption of CR dye removal from its aqueous solution using MSC as adsorbent are intra-particle (Weber-Morris) (Eq. 9) and Boyd diffusion kinetic models (Eqs. 10-13).

Generally, adsorption process is governed by internal or external mass transfer or both (Sartape et al. 2014). Inability of graph of $q_{\mathrm{t}} \mathrm{Vs} t^{0.5}$ to pass through the origin (Fig. 11) and value of $C>0$ (Table 4) indicated that along with intra-particle diffusion other mechanism is involved in adsorption process (Vasanth et al. 2005). Biphasic nature of the graph showed that either film or pore (particle) diffusion is involved in the CR dye adsorption process (Nethaji et al. 2013).

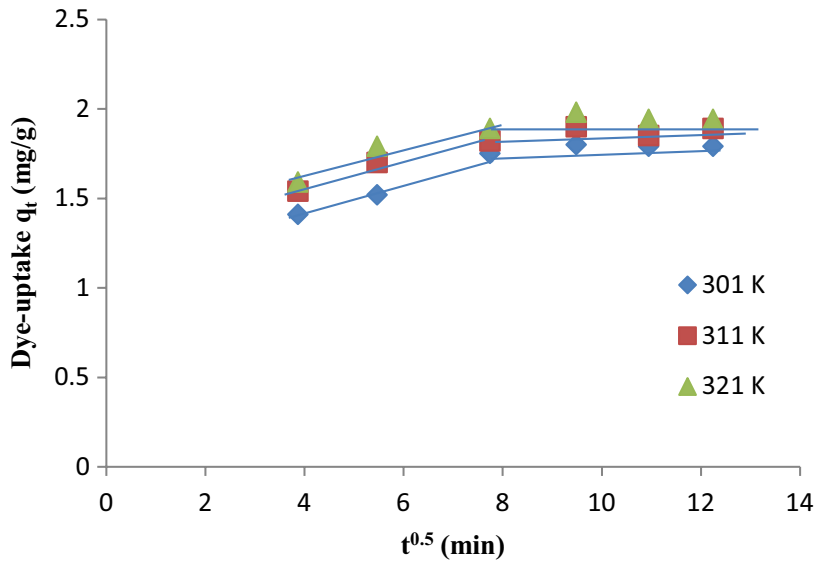

Fig. 11 Intraparticle diffusion plots for adsorption of CR dye on MSC at different temperatures

Table 4 Adsorption mechanism parameters for adsorption of CR dye on MSC at different temperatures

\begin{tabular}{llll}
\hline Parameter & \multicolumn{2}{l}{ Temperature $(\mathrm{K})$} \\
\cline { 2 - 4 } & 301 & 311 & 321 \\
\hline Intraparticle diffusion & & & \\
$K_{\mathrm{id}}\left(\mathrm{mgg}^{-1} \mathrm{~min}^{-1}\right)$ & 0.0477 & 0.0391 & 0.0394 \\
$C\left(\mathrm{mgg}^{-1}\right)$ & 1.2809 & 1.4592 & 1.5280 \\
$R^{2}$ & 0.8331 & 0.8183 & 0.7634 \\
Boyd expression & & & \\
$B\left(\mathrm{~min}^{-1}\right)$ & 0.0245 & 0.0153 & 0.0166 \\
$C$ & 0.8198 & 1.4533 & 1.2010 \\
$R^{2}$ & 0.9378 & 0.8006 & 0.9154 \\
$D_{\mathrm{i}} \times 10^{-5}\left(\mathrm{~cm}^{-2} \mathrm{~g}^{-1} \mathrm{~min}^{-1}\right)$ & 0.14 & 8.85 & 9.60 \\
\hline
\end{tabular}




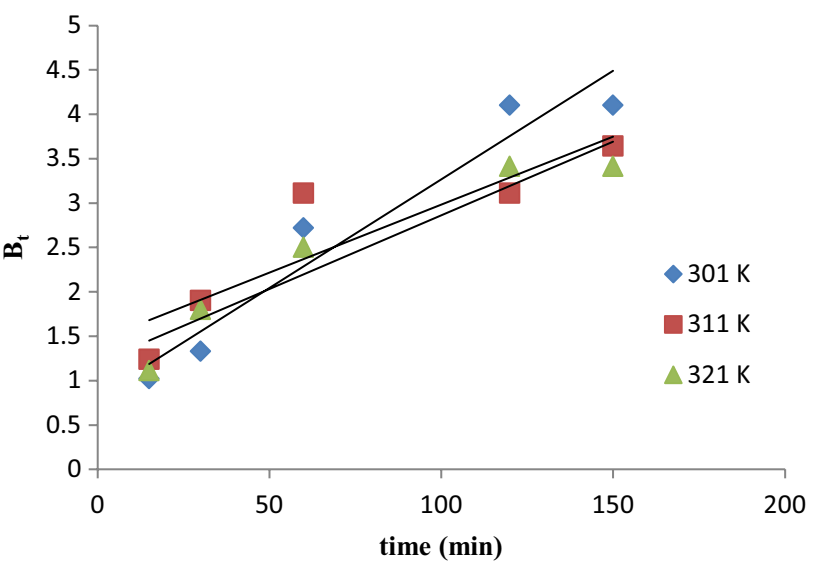

Fig. 12 Boyd kinetic plots for adsorption of CR dye on MSC at different temperatures

Boyd kinetic model was use to confirm either film or pore diffusion was involved in the process. This confirmation was done with the aid of graph of $B \mathrm{t} \mathrm{Vs} t$ (Fig. 12). Inability of the linear plot to pass through the origin confirmed the adsorption mechanism is governed by film diffusion mechanism. This indicated that external transport of CR dye is more than internal transport (Sartape et al. 2014).

The slope $(B)$ of $B_{\mathrm{t}} \mathrm{Vs} t$ is time constant, which is related to diffusion coefficient $D_{\mathrm{i}}$ in Eqs. 17 and 18 (Kumar et al. 2006).

$B=\frac{\pi^{2}}{r^{2}} D_{\mathrm{i}}$

$D_{\mathrm{i}}=\frac{B}{\pi \mathrm{A}}$

The value of $B\left(\mathrm{~min}^{-1}\right)$ was gotten from the slope of $B_{t} \mathrm{Vs} t$, and surface area $A\left(\mathrm{~cm}^{2} \mathrm{~g}\right)$ was obtained from physicochemical characterization of MSC (Table 1). Values of parameters from adsorption mechanism are presented in Table 4.

The values of effective diffusion coefficient $D_{\mathrm{i}}$ $\left(\mathrm{cm}^{-2} \mathrm{~g}^{-1} \mathrm{~min}^{-1}\right)$ calculated at 301,311 and $321 \mathrm{~K}$ not fallen between 10 and $11 \mathrm{~cm}^{-2} \mathrm{~g}^{-1} \mathrm{~min}^{-1}$ are a further confirmation of rate determining step not particle diffusion but film diffusion mechanism (Kumar et al. 2006).

\section{Conclusion}

MSC adsorbent was prepared through mercerization of $M$. oleifera seed coat. It was used to investigate removal of CR dye from aqueous solution. SEM characterization indicated surface morphology of MSC to be rough with irregular shape and several pores accounting for physical removal (physisorption) of CR dye from aqueous solution.
FTIR displayed appearance of new peaks at 3419.90, 1172.76 and $698.25-669.32 \mathrm{~cm}^{-1}$ on MSC after adsorption process, confirming electrostatic attraction (chemisorption) of $\mathrm{CR}$ dye onto MSC through $-\mathrm{NH}_{2}, \mathrm{C}-\mathrm{N}$ and $\mathrm{SO}_{3}{ }^{-}$functional groups, respectively, in CR dye. $>90 \%$ of $\mathrm{CR}$ dye was removed from aqueous solution at optimum adsorption temperature and contact time $321 \mathrm{~K}$ and $90 \mathrm{~min}$, respectively. Adsorption kinetic followed pseudosecond-order model, indicating chemisorption nature of the process and activation energy $\left(E_{\mathrm{a}}\right)<40 \mathrm{~kJ} / \mathrm{mol}$ confirmed inclusion of physiosorption in adsorption process. The mechanism of adsorption process showed film diffusion as adsorption rate determining step. Finally, MSC can be considered as an effective alternative adsorbent to CAC for treatment of wastewater polluted by CR dye.

Acknowledgements The authors are highly thankful to the Federal Government of Nigeria for awarding Tertiary Education Trust Fund (2016) grants to Polymer and Textile research group, Department of Chemistry, the Federal University of Technology, Akure (FUTA) where laboratory facilities for the success of this research work were obtained.

\section{Compliance with ethical standards}

Conflict of interest The authors hereby declared that we have no competing interest.

Open Access This article is licensed under a Creative Commons Attribution 4.0 International License, which permits use, sharing, adaptation, distribution and reproduction in any medium or format, as long as you give appropriate credit to the original author(s) and the source, provide a link to the Creative Commons licence, and indicate if changes were made. The images or other third party material in this article are included in the article's Creative Commons licence, unless indicated otherwise in a credit line to the material. If material is not included in the article's Creative Commons licence and your intended use is not permitted by statutory regulation or exceeds the permitted use, you will need to obtain permission directly from the copyright holder. To view a copy of this licence, visit http://creativecommons.org/licenses/by/4.0/.

\section{References}

Aljeboree AM, Alshirrifi AN, Alkaim AF (2014) Kinetics and equilibrium study for the adsorption of textile dyes on coconut shell activated carbon. Arab J Chem. https://doi.org/10.1016/j.arabj c. 2014.01 .020

AlOthman ZA, Habila MA, Ali R, Abdel A, Ghafar MS, Eldin H (2013) Valorization of two waste streams into activated carbon and studying its adsorption kinetics equilibrium isotherms and thermodynamics for methylene blue removal. Arab J Chem 2:2-12. https://doi.org/10.1016/j.arabjc.2013.05.007

Amaranatha RD, Lee S, Choi J, Park S, Ma R, Yang H, Kim TK (2015) Green synthesis of AgI-reduced graphene oxide nanocomposites: toward enhanced visible-light photocatalytic activity for organic dye removal. Appl Surf Sci 341:175-184

Arrhenius S (1889) Uber die reaktionsgeschwindigkeit bei inversion von rohrzucker durch sauren. J Phys Chem 14:226

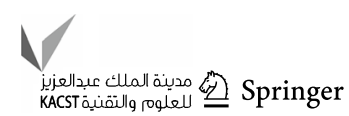


Babu SS, Mohandass C, Vijayaraj AS, Dhale AM (2015) detoxification and color removal of congo red by a novel dietzia sp. (dts26)—a microcosm approach. Ecotoxicol Environ Safety 114:52-60

Banerjee S, Chattopahyaya MC (2017) Adsorption characteristics for the removal of a toxic dye, tartrazine from aqueous solutions by low cost agricultural by-product. Arab J Chem 10:S1629-S1638. https://doi.org/10.1016/j.arabjc.2013.06.005

Bayuo J, Pelig-Ba KB, Abukari MA (2019) Adsorptive removal of chromium(VI) from aqueous solution unto groundnut shell. Appl Water Sci 9:107

Bello OS, Adegoke KA, Akinyunni OO (2017) Preparation and characterization of a novel adsorbent from Moringa oleifera leaf. Appl Water Sci 7:1295-1305

Bello OS, Ahmad MA (2012) Coconut (Cocos nucifera) shell based activated carbon for the removal of malachite green dye from aqueous solutions. Sep Sci Technol 47:903-912

Bello OS, Ahmad MA, Siang TT (2011) Utilization of cocoa pod husk for the removal of Remazol Black B reactive dye from aqueous solutions: kinetic, equilibrium and thermodynamic studies. Trends Appl Sci Res 6(8):794-812

Bello OS, Semire B (2012) Equilibrium, kinetic and quantum chemical studies on the adsorption of Congo red using Imperata cylindrica leaf powder activated carbon. Toxicol Environ Chem 94:1114-1124

Bhattacharrya K, Sharma A (2004) Azadirachta indica leaf powder as an effective biosorbent for dyes: a case study with aqueous congo red solutions. J Environ Manag 71:217-229

Bhaumik M, McCrindle R, Maity A (2013) Efficient removal of Congo red from aqueous solutions by adsorption onto interconnected polypyrrole-polyaniline nanofibres. Chem Eng J 228:506-515

Boulaiche W, Hamdi B, Trari M (2019) Removal of heavy metals by chitin: equilibrium, kinetic and thermodynamic studies. Appl Water Sci 9:39

Boyd GE, Adamson AW, Myers LS Jr (1947) The exchange adsorption of ions from aqueous solutions by organic zeolites II: kinetics. J Am Chem Soc 69:2836

Chan-Li H, Yu-wen LY, Chil-Chang H, Yao-Hui H, Chunch-Yung C (2007) Adsorption kinetic, thermodynamic and desorption studies of C.I. reactive black 5, on a novel photo assisted fento catalyst. Dyes Pigm 75:130-135

Chatterjee S, Chatterjee S, Chatterjee BP, Guha AK (2007) Adsorptive removal of congo red, a carcinogenic textile dye by chitosan hydrobeads: binding mechanism, equilibrium and kinetics. Colloids Surf A Physicochem Eng Asp 299:146-152

Chatterjee SM, Lee W, Woo SH (2010) Adsorption of congo red by chitosan hydrogel beads impregnated with carbon nanotubes. Biores Tech 101:1800-1806

Chen H, Zhao J (2009) Adsorption study for removal of congo red anionic dye using organo-attapulgite. Adsorption 15:381-389

Cheng Z, Zhang L, Guo X, Jiang X, Li T (2015) Adsorption behavior of direct red 80 and congo red onto activated carbon/ surfactant: process optimization, kinetics and equilibrium. Spectrochim Acta Part A Mol Biomol Spectrosc 137:1126-1143

Christie RM (2015) Colour chemistry, 2nd edn. The Royal Society of Chemistry, Cambridge

Chukki J, Abinandan S, Shanthakumar S (2018) Chrysanthemum indicum microparticles on removal of hazardous congo red using response surface methodology. Int J Ind Chem 9:305-316

Darwish AAA, Rashad M, Al-Aoh HA (2019) Methyl orange adsorption comparison on nanoparticles: Isotherm, kinetics and thermodynamic studies. Dyes Pigm 160:563-571

Deng L, Shi Z (2015) Synthesis and characterization of a novel Mg-Al hydrotalcite-loaded kaolin clay and its adsorption properties for phosphate in aqueous solution. J Alloys Comp 637:188-196
Dhaif-Allah MAH, Taqui SN, Syed UT, Syed AA (2020) Kinetic and isotherm modeling for acid blue adsorption onto low-cost nutraceutical industrial fenugreek seed spent. Appl Water Sci 10:58. https://doi.org/10.1007/s13201-20-1141-3

Etim UJ, Umoren SA, Eduok UM (2016) Coconut coir dust as low cost adsorbent for the removal of cationic dye from aqueous solution. J Saudi Chem Soc 20:S67-S76

El Haddad M, Slimani R, Mamouni R, ElAntri S, Lazar S (2013) Removal of two textile dyes from aqueous solutions onto calcined bones. J Assoc Arab Uni Basic Appl Sci 14:51-59. https://doi. org/10.1016/j.jaubas.2013.03.002

Fisli A, Yusuf S, Ridwan YK, Krisnandi JG (2014) Preparation and characterization of magnetite-silica nano-composite as adsorbents for removal of methylene blue dyes from environmental water samples. Adv Mater Res 896:525-531

Hameed BH, Almad AL, Latiff KNA (2007) Adsorption of basic dye (methylene blue) onto activated carbon prepared from rattan sawdust. Dyes Pigm 75:143-149

Hameed KS, Muthirulan P, Meenakshi SM (2013) Adsorption of chromotrope dye onto activated carbons obtained from the seeds of various plants: equilibrium and kinetics studies. Arab J Chem. https://doi.org/10.1016/j.arabjc.2013.07.058

Han R, Ding D, Xu Y, Zou W, Wang Y, Li Y, Zou L (2008) Use of rice husk for the adsorption of congo red from aqueous solution in column mode. Biores Tech 99:2938-2946

Hu Z, Chen H, Ji F, Yuan S (2010) Removal of congo red from aqueous solution by cattail root. J Hazard Mater 173:292-297

Jabar JM, Odusote YA (2020) Removal of cibacron blue 3G-A (CB) dye from aqueous solution using chemo-physically activated biochar from oil palm empty fruit bunch fiber. Arab J Chem. https:// doi.org/10.1016/j.arabjc.2020.03.020

Jethava G, Fegade U (2018) Design and synthesis of $\mathrm{Zn}_{0.3} \mathrm{Fe}_{0.45} \mathrm{O}_{3}$ nanoparticle for efficient removal of congo red dye and its kinetic and isotherm investigation. Int J Ind Chem 9:85-97

Kumar KV, Kumaran A (2005) Removal of Methylene blue by mango seed kernel powder. Biochem Eng J 27:83-93

Kumar KV, Ramamurthi V, Sivanesan S (2006) Biosorption of malachite green, a cationic dye onto Pithophora sp., a fresh water algae. Dyes Pigm 69:102

Li S (2019) Combustion synthesis of porous $\mathrm{MgO}$ and its adsorption properties. Int J Ind Chem 10:89-96. https://doi.org/10.1007/ s40090-019-0174-7

Liu S, Ding Y, Li P, Diao K, Tan X, Lei F, Zhan Y, Li Q, Huang B, Huang $Z$ (2014) Adsorption of the anionic dye Congo red from aqueous solution onto natural zeolites modified with $N$, Ndimethyl dehydroabietylamine oxide. Chem Eng J 248:135-144

Nethaji S, Sivasamy A, Mandal AB (2013) Adsorption isotherms, kinetics and mechanism for the adsorption of cationic and anionic dyes onto carbonaceous particles prepared from Juglans regia shell biomass. Int J Environ Sci Technol 10:231-242

Omidi-Khaniabadi Y, Heydari R, Nourmoradi H, Basiri H, Basiri H (2016) Low-cost sorbent for the removal of aniline and methyl orange from liquid-phase: aloe vera leaves wastes. J Taiwan Inst Chem Engr 68:90-98

Omidi-Khaniabadi Y, Jafari A, Nourmoradi H, Taheri F, Saeedi S (2015) Adsorption of 4-chlorophenol from aqueous solution using activated carbon synthesized from aloe vera green wastes. J Adv Environ Health Res 3:120-129

Ozsin G, Kılıc M, Apaydın-Varol E, Putun AE (2019) Chemically activated carbon production from agricultural waste of chickpea and its application for heavy metal adsorption: equilibrium, kinetic, and thermodynamic studies. Appl Water Sci 9:56

Pathania D, Sharma S, Singh P (2017) Removal of methylene blue by adsorption onto activated carbon developed from Fiscus carica Bast. Arab J Chem 10:S1445-S1451 
Pura S, Atun G (2009) Adsorptive removal of acid Blue 113 and tartrazine by fly ash from single and binary dye solutions. J Sep Sci Technol 44:75

Reddy M, Sivaramakrishna L, Reddy A (2012) The use of an agricultural waste material, jujuba seeds for the removal of anionic dye (congo red) from aqueous medium. J Hazard Mater 203-204:118-127

Rong X, Qiu F, Qin J, Zhao H, Yan J, Yang D (2015) A facile hydrothermal synthesis, adsorption kinetics and isotherms to Congo Red azo-dye from aqueous solution of $\mathrm{NiO} /$ grapheme nanosheets adsorbent. J Ind Eng Chem 26:354-363

Salleh MAM, Mahmoud DK, Karim WA, Idris A (2011) Cationic and anionic dye adsorption by agricultural solid wastes: a comprehensive review. Desalination 280:1-13

Sartape AS, Mandhare AM, Jadhav VV, Raut PD, Anuse MA, Kolekar SS (2014) Removal of malachite green dye from aqueous solution with adsorption technique using Limonia acidissima (wood apple) shell as low cost adsorbent. Arab J Chem. https://doi. org/10.1016/j.arabjc.2013.12.019

Siddhuraju P, Becker K (2003) Antioxidant properties of various solvent extract of total phenolic constituents from different agroclimaticorigins of drumstick tree (Moringa oleifera Lam) leaves. J Agric Food Chem 51(8):2144-2155
Somasekharareddy MC, Sivaramakrishna L, Varadareddy A (2012) The use of an agricultural waste material, Jujuba seeds for the removal of anionic dye (Congo red) from aqueous medium. J Hazard Mater 203-204:118-127

Tang L, Cai Y, Yang G, Liu Y, Zeng G, Zhou Y, Li S, Wang J, Zhang S, Fang Y, He Y (2014) Cobalt nanoparticles-embedded magnetic ordered mesoporous carbon for highly effective adsorptionof rhodamine B. Appl Surf Sci 314:746-753

Vasanth KK, Ramamurthi V, Sivanesan S (2005) Modeling the mechanism involved during the sorption of methylene blue onto fly ash. J Colloid Interface Sci 284:14-21

Yan L, Shan R, Yan T, Wei J, Yu S, Yu H, Du B (2015) Kinetic, isotherm and thermodynamic investigations of phosphate adsorption onto core-shell $\mathrm{Fe}_{3} \mathrm{O}_{4} @$ LDHscomposites with easy magnetic separation assistance. J Colloid Interface Sci 448:508-516

Zhang Z, Moghaddam L, O'Hara IM, Doherty WOS (2011) Congo red adsorption by ball-milled sugarcane bagasse. Chem Eng $\mathrm{J}$ $178: 122-128$

Publisher's Note Springer Nature remains neutral with regard to jurisdictional claims in published maps and institutional affiliations. 